\title{
"Cahiers Mérimée" 11
}

\author{
Michel Arrous
}

\section{(2) OpenEdition}

\section{Journals}

\section{Édition électronique}

URL : https://journals.openedition.org/studifrancesi/45299

DOI : $10.4000 /$ studifrancesi.45299

ISSN : 2427-5856

\section{Éditeur}

Rosenberg \& Sellier

\section{Édition imprimée}

Date de publication : 1 août 2021

Pagination : 390-391

ISSN : 0039-2944

\section{Référence électronique}

Michel Arrous, " "Cahiers Mérimée" 11 », Studi Francesi [En ligne], 194 (LXV | II) | 2021, mis en ligne le 01 septembre 2021, consulté le 15 octobre 2022. URL : http://journals.openedition.org/studifrancesi/ 45299 ; DOI : https://doi.org/10.4000/studifrancesi.45299

Ce document a été généré automatiquement le 15 octobre 2022.

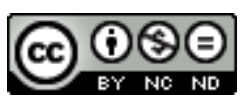

Creative Commons - Attribution - Pas d'Utilisation Commerciale - Pas de Modification 4.0 International - CC BY-NC-ND 4.0

https://creativecommons.org/licenses/by-nc-nd/4.0/ 


\title{
"Cahiers Mérimée" 11
}

\author{
Michel Arrous
}

\section{RÉFÉRENCE}

"Cahiers Mérimée" 11, Paris, Classiques Garnier, 2019, 208 pp.

1 Alors qu'on a longtemps privilégié le nouvelliste au détriment de l'historien ou de l'archéologue, Xavier BOURDENET considère les liens génétiques entre histoire et fiction et le glissement de l'une à l'autre (Mérimée, la fiction dans les marges de l'histoire. "Carmen" et "Don Pèdre", pp. 11-32). On sait qu'à partir de 1846 l'écriture érudite a servi de relais à l'écriture fictionnelle, à la fois comme "dérivatif» ou comme "remède» à la crise amoureuse. Ce «tournant érudit» est à nuancer car, avant cette date et parallèlement aux œuvres de fiction, l'œuvre historique est travaillée par la fiction selon quatre dispositifs: la greffe (la pièce Les Débuts d'un aventurier comble les silences de l'histoire puisque Mérimée imagine la jeunesse du faux Démétrius), la germination, quand l'histoire suscite la fiction (Carmen), l'entrelacs (dans Stenka Razine, à la rigueur de l'historien se mêle la légende véhiculée par les poésies populaires), la contamination ou la surimpression (dans l'Histoire de la fausse Élisabeth II, si aucune œuvre fictionnelle ne naît du compte rendu de l'historien, ce travail est néanmoins influencé par le romanesque). La germination est étudiée en détail dans le cas de Carmen qui s'écrit «littéralement» dans les marges du Don Pèdre dont certains éléments sont transposés dans la nouvelle. Ce sont les rapports de l'écrivain avec ses éditeurs, d'après les nombreuses lettres qu'il leur a adressées de 1825 à 1870 que Barbara Dimopoulou a entrepris d'examiner (Mérimée et ses éditeurs. Premiers aperçus, pp. 33-61). Du choix des éditeurs dépend bien sûr la qualité de la réception des œuvres; aussi voit-on Mérimée, informé des contraintes techniques, se préoccuper scrupuleusement des affaires de son métier et s'impliquer dans les tâches propres à la réalisation de ses livres, qu'il s'agisse de ses propres œuvres ou de ses travaux d'éditeur scientifique, par exemple quand il intervient en «censeur redoutable» pour les đuvres complètes et la Correspondance inédite de Stendhal. 
2 Suivent deux études de Lokis, "sujet le plus extravagant et le plus atroce», de l'avis même de Mérimée. Sylvie THOREL propose de décrypter le récit fantastique de 1868 (Apprivoiser son griffon, un aspect de la fiction selon Mérimée, pp. 63-74). L'intérêt de cette relecture est de mettre en évidence chez cet écrivain rusé une théorie de la fiction selon laquelle érudition et mystification vont de pair. Pour sa part, Anne ORSET voit dans le journal du professeur Wittembach un traité pré-psychanalytique qui serait à la fois un manuel de linguistique comparée, un carnet de voyage, et un rapport d'aliéniste, à une époque où l'on débat de différentes théories du rêve ("Lokis", essai d'onirologie contemporaine, pp. 75-91). D'où une relecture du fameux manuscrit, notamment le récit de cauchemar et l'analyse de la psyché du comte, au prisme des analyses onirologiques de Maury. On quitte l'inconscient pour une histoire que Mérimée a osé lire à l'Impératrice pour la distraire, en prenant soin d'éviter toute provocation. Comme l'a dit Jean Bellemenin-Noël, c'est l'histoire d'«une chambre trop bleue pour être honnête», à la fois «fort immorale» et «fort morale au fond», à quelques détails près, précise Mérimée. Dans cette histoire riche en sous-entendus et qui tient du vaudeville, Daniel-Henri PAGEAUX met en évidence l'habileté du conteur qui pastiche par endroits Labiche et multiplie les effets d'intertextualité avec La Vénus d'Ille, Vision de Charles IX et même Madame Bovary (Un conte bleu. "La Chambre bleue", pp. 93-111).

3 À de rares exceptions près, on a longtemps soutenu la thèse selon laquelle Mérimée se serait engagé dans la sauvegarde et la restauration du patrimoine médiéval alors qu'il n'avait de goût et d'intérêt que pour le modèle antique. La nouvelle appréciation de l'œuvre et des idées de Mérimée en matière d'archéologie médiévale date des années 1970. Dans son essai La formation du savoir et du goût. Prosper Mérimée face aux monuments médiévaux (pp.113-138), Alexandre BONAFos reconstitue son approche des monuments médiévaux et de l'art de la construction entre 1834 et 1839, en partie héritée des réflexions des théoriciens français ainsi que des recherches archéologiques anglaises du XVIII siècle sur la classification des édifices, la définition des époques et l'évolution du modèle médiéval. Dans ses tournées, Mérimée, à la fois historien de l'art et critique d'art, souligne l'intérêt de chaque période et découvre des édifices foncièrement différents de ce que les antiquaires anglais avaient décrit. À son analyse de la construction du monument et de son évolution s'ajoute une appréciation esthétique parfois mitigée (par exemple pour la sculpture figurative romane). Selon sa perspective historique, dans l'art roman prime la force, alors que la puissance intellectuelle l'emporte à la période gothique, avant que ses excès n'annoncent la décadence qu'il voit dans le gothique flamboyant. Sensible à l'expression esthétique du Moyen Âge, l'auteur de l'Essai sur l'architecture religieuse (1837) a pu mener à bien son travail de classification et de restauration. En dépit de son titre, l'article publié dans la "Revue des deux mondes" le 15 octobre 1857, où l'on retrouve d'ailleurs des idées exprimées dans les deux Salons de 1839 et 1853, a pour sujet principal la réforme de l'enseignement du dessin au Royaume-Uni. Dans "De l'état des Beaux-Arts en Angleterre en 1857" ou de la question de l'art appliqué à l'industrie (pp. 139-158), Christophe LONGBOISCANIL, après avoir rappelé les réserves de Mérimée sur les portraitistes anglais et les préoccupations des préraphaélites, ou sa réaction face à W.H. Hunt, analyse la seconde partie du texte consacrée à la politique culturelle britannique, sujet déjà abordé dans l'article Exposition de Manchester. Pour Mérimée, il y a un «enseignement à tirer de ce système pour la France». 
Une section «Enseignement» propose deux des travaux présentés au séminaire Mérimée (Paris III) par des enseignants et des étudiants de l'Université de l'État de Louisiane. Grâce à la technologie de Google Maps, Rosemary PETERS-HILL, avec la collaboration de Claire LA GRONE, a établi une carte virtuelle pour suivre le périple de l'héroüne, dans la nouvelle comme dans une dizaine d'adaptations à l'hispanité fort variable et où un «flou spatial» remplace les localisations précises données par Mérimée (Carmentographie. Pour une map de Mérimée, pp.165-175). On constate de nombreuses contradictions entre la géographie du récit et la réalité géographique. La lecture cartographique favorise-t-elle la compréhension de la nouvelle? À tout le moins, elle incite à s'interroger sur les mouvements de l'insaisissable bohémienne. Il s'agissait donc de lire Carmen, mais autrement, par exemple en modifiant certains éléments de cette histoire si connue, comme l'a fait Sophie Rabau (Carmen, pour changer. Variations sur une nouvelle de Prosper Mérimée, 2018). Rachelle Mosing analyse les clips vidéos de la Carmen de Gipsy, dans la version Netflix de 2016, laquelle exploite le livret plus que la nouvelle (Une Carmen perdue, une Carmen pour une nouvelle génération, pp.177-184). Autant de lectures qui illustrent l'intemporalité du personnage de Carmen.

5 Xavier BOURDENET poursuit sa bibliographie de la critique (pp. 193-202) sur l'œuvre pour 2017, avec des compléments pour 2001, 2007 et 2016; A. BONAFOs donne la «Bibliographie de la critique sur l'œuvre et les activités de Mérimée dans les domaines de l'art et de l'archéologie» pour 2017. 